\title{
Percepções de pessoas com tuberculose/HIV em relação à adesão ao tratamento
}

Perceptions of people with tuberculosis/HIV regarding treatment adherence

Percepción de personas con tuberculosis/VIH con relación a la adherencia al tratamiento

Alexandra Rodrigues dos Santos Silva ${ }^{1}$ (D https://orcid.org/0000-0002-1408-196x

Paula Hino ${ }^{1}$ (D) https://orcid.org/0000-0002-1408-196X

Maria Rita Bertolozzi² (D https://orcid.org/0000-0002-5009-5285 Julia Couto de Oliveira ${ }^{1}$ iD https://orcid.org/0000-0002-2311-7143 Marcos Vinícius de Freitas Carvalho ${ }^{1}$ io https://orcid.org/0000-0003-4633-413X

Hugo Fernandes ${ }^{1}$ io https://orcid.org/0000-0003-2380-2914

Sumire Sakabe ${ }^{3}$ io https://orcid.org/0000-0002-9054-2844

Como citar:

Silva AR, Hino P, Bertolozzi MR, Oliveira JC, Carvalho MV, Fernandes H, et al. Percepções de pessoas com tuberculose/HIV em relação à adesão ao tratamento. Acta Paul Enferm. 2022;35:eAPE03661.

DOI

http://dx.doi.org/10.37689/acta-ape/2022A003661

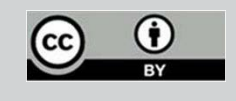

Descritores

Adesão à medicação; Coinfecção; HIV; Tuberculose

Keywords

Medication adherence; Coinfection; HIV; Tuberculosis

Descriptores

Cumplimiento de la medicación; Coinfección; VIH;

Tuberculosis

$$
\begin{array}{r}
\text { Submetido } \\
5 \text { de Dezembro de } 2020 \\
\text { Aceito }
\end{array}
$$

25 de Março de 2021

Autor correspondente Alexandra Rodrigues dos Santos Silva E-mail: alexandra.rodrigues@unifesp.br

Editor Associado (Avaliação pelos pares): Alexandre Pazetto Balsanelli (https://orcid.org/0000-0003-3757-1061) Escola Paulista de Enfermagem, Universidade Federal de São Paulo, São Paulo, SP, Brasi

\section{Resumo}

Objetivo: Analisar aspectos relacionados à adesão ao tratamento da tuberculose em pessoas que vivem com coinfecção tuberculose/vírus da imunodeficiência humana.

Métodos: Trata-se de um estudo exploratório, do tipo descritivo, com abordagem qualitativa sobre a adesão ao tratamento da tuberculose entre pessoas que apresentam a coinfecção tuberculose/vírus da imunodeficiência humana. 0 cenário do estudo foi um centro de referência para vírus da imunodeficiência humana/síndrome da imunodeficiência adquirida do estado de São Paulo, localizado na capital. 0 instrumento de coleta de dados continha questões relacionadas ao perfil sóciodemográfico e de saúde. Para a análise do material empírico foi utilizado o método de análise de discurso que permitiu a depreensão de frases temáticas.

Resultados: Foram entrevistadas 16 pessoas, sendo a maioria do sexo masculino, da cor parda, na faixa etária entre 30 a 39 anos, com 9 a 12 anos de estudo, que moravam sozinhos, solteiros e que se declararam homossexuais. Da análise dos depoimentos emergiram três categorias de análise: Processo saúde doença: o impacto do diagnóstico e os significados de viver a coinfecção; Tratamento medicamentoso: motivos para o seguimento, facilidades e dificuldades envolvidas; e Cuidado no serviço de saúde: acolhimento e redes de apoio que favorecem a adesão ao tratamento.

Conclusão: A adesão ao tratamento na coinfecção tuberculose/vírus da imunodeficiência humana mostrou-se relacionada à forma como a pessoa está inserida na sociedade, suas condições de vida e trabalho. Ressaltase também que o cuidado nos serviços de saúde interfere na adesão, dada a importância do vínculo entre 0 profissional de saúde e o usuário.

\section{Abstract}

Objective: To analyze aspects related to adherence to tuberculosis treatment in people living with tuberculosis/ human immunodeficiency virus coinfection.

Methods: This is an exploratory, descriptive, qualitative study on adherence to tuberculosis treatment among people with tuberculosis/human immunodeficiency virus coinfection. The study setting was a reference center for human immunodeficiency virus/acquired immunodeficiency syndrome located in the capital of the state of São Paulo. The data collection instrument contained socio-demographic and health profile related questions. The discourse analysis method was used for the analysis of the empirical material, which allowed the comprehension of thematic phrases.

Results: Sixteen people were interviewed. Most were male, mixed race, in the age group of 30-39 years, with 9-12 years of study, living alone, single and declared themselves homosexuals. Three categories of analysis emerged from the analysis of testimonies: Health-disease process: the impact of the diagnosis and 
the meanings of living with coinfection; Drug treatment: reasons for follow-up, facilities and difficulties involved; and Care in the health service: embracement and support networks that favor treatment adherence.

Conclusion: Adherence to treatment in the tuberculosis/human immunodeficiency virus coinfection has shown a relation to the way people are inserted in society, their living and working conditions. The fact that care in health services interferes with adherence is also noteworthy, given the importance of the bond between the health professional and the user.

\section{Resumen}

Objetivo: Analizar los aspectos relacionados con la adherencia al tratamiento de tuberculosis en personas que viven con la coinfección tuberculosis/virus de la inmunodeficiencia humana.

Métodos: Se trata de un estudio exploratorio, tipo descriptivo, con enfoque cualitativo, sobre la adherencia al tratamiento de tuberculosis en personas que presentan la coinfección tuberculosis/virus de la inmunodeficiencia humana. El escenario de estudio fue un centro de referencia del virus de la inmunodeficiencia humana/síndrome de inmunodeficiencia adquirida del estado de São Paulo, ubicado en la capital. El instrumento de recopilación de datos contenía preguntas relacionadas con el perfil sociodemográfico y de salud. Para analizar el material empírico se utilizó el método de análisis de discurso que permitió extraer frases temáticas.

Resultados: Se entrevistaron 16 personas, de las cuales la mayoría era de sexo masculino, de color pardo, del grupo de edad entre 30 y 39 años, con 9 a 12 años de estudios, que vivían solos, solteros y que se declararon homosexuales. Del análisis de los relatos surgieron tres categorías de análisis: Proceso de salud y enfermedad: el impacto del diagnóstico y los significados de vivir la coinfección; Tratamiento farmacológico: motivos para el acompañamiento, facilidades y dificultades relacionadas, y Cuidado en el servicio sanitario: contención y redes de apoyo que favorecen la adherencia al tratamiento.

Conclusión: La adherencia al tratamiento de la coinfección tuberculosis/virus de la inmunodeficiencia humana demostró estar relacionada con la forma como la persona está insertada en la sociedad, su condición de vida y trabajo. También se observó que el cuidado en los servicios de salud interfiere en la adherencia, debido a la importancia del vínculo entre los profesionales de la salud y los usuarios.

\section{Introdução}

A magnitude epidemiológica da tuberculose (TB) representa uma ameaça global à saúde..$^{(1)} \mathrm{A}$ doença está entre uma das dez principais causas de morte entre as doenças infecciosas e é a principal causa em pessoas vivendo com vírus da imunodeficiência humana (HIV) e síndrome da imunodeficiência adquirida (AIDS) (PVHA). Em 2019, 10 milhóes de pessoas adoeceram por TB no mundo, sendo que $8,2 \%$ viviam com HIV. Do total de casos de TB, 1,2 milhão de pessoas evoluiu para óbito e, destas, 208.000 mortes ocorreram entre PVHA. ${ }^{(2)}$

A Organização das Naçôes Unidas (ONU) e a Organização Mundial da Saúde (OMS) continuadamente apresentam estratégias para o controle da doença. A TB faz parte dos Objetivos do Desenvolvimento Sustentável (ODS) evidenciada pela Estratégia Fim da TB, lançada em 2014 pela OMS, que visa alcançar um mundo livre da doença e de sofrimento decorrente da enfermidade, além de mortes até 2035. ${ }^{(2)}$ A fim de consolidar esses objetivos, o Ministério da Saúde brasileiro estabeleceu, a partir de 2017, o Plano Nacional pelo Fim da Tuberculose, que busca reduzir o coeficiente de incidência para menos de 10 casos por 100 mil habitantes e o coeficiente de mortalidade por
TB para menos de 1 óbito por 100 mil habitantes até 2035. ${ }^{(1)}$

Dentre os países prioritários, o Brasil ocupa a $19^{a}$ posição no que se refere à coinfecção TB/HIV, com taxa de abandono do tratamento de $11,6 \%$ e cura de $71,9 \%$ em 2019. ${ }^{(1)}$ Tais índices revelam distanciamento em relaçáo ao recomendado, estabelecido em $5 \%$ e maior que $85 \%$, respectivamente. ${ }^{(3)}$

Os desfechos desfavoráveis (abandono e óbito) e as falhas no sucesso do tratamento da TB, entre as pessoas que apresentam a coinfecção TB-HIV chamam a atenção e clamam por estudos que busquem identificar os determinantes da não adesão ao tratamento. ${ }^{(4)}$

A dificuldade do manejo da TB em PVHA pode ser justificada por motivos tais como: interaçóes medicamentosas com antirretrovirais, desenvolvimento de resistência às drogas e longa duração da terapêutica. ${ }^{(5)}$ Ademais, as PVHA estão mais propensas a desenvolver a $\mathrm{TB}$, quando comparadas à população geral, em decorrência da supressão imunológica. Soma-se a isso, as iniquidades sociais e em saúde, o que constitui um desafio especial para o controle da TB e, da coinfecçáo TB/HIV. ${ }^{(\oplus)}$

As consequências do HIV/aids vão além do quadro clínico, tendo também implicaçóes mentais e sociais, entendendo-se a interdependência intrínse- 
ca entre esses aspectos. Assinala-se que a coinfecção TB/HIV pode aumentar o estigma levando, não raro, à rejeição familiar e de outras pessoas da convivência. Além disso, a não adesão ao tratamento pode implicar na piora da evolução da coinfecção, com desdobramentos na qualidade de vida (QV). ${ }^{(7)}$

Enquanto o tratamento da TB é realizado durante o período de, no mínimo, seis meses, com possibilidade de cura na quase totalidade dos casos, o tratamento do HIV/aids é contínuo durante toda a vida. Nessa perspectiva, supóe-se que as PVHA e que realizam o tratamento da TB podem representar um grupo de maior vulnerabilidade a náo seguir o tratamento, principalmente em decorrência dos potenciais efeitos adversos dos medicamentos antituberculose e da terapia antirretroviral (TARV). A sua intolerância, além de outros aspectos, relativos à evolução da coinfecção, podem levar ao abandono do tratamento, com repercussóes na QV dos pacientes. ${ }^{(4,8)}$

Reconhecendo a importância da adesão ao tratamento em pessoas que vivem com a coinfecção TB/HIV, a presente investigação foi norteada pela seguinte questão: Quais aspectos envolvem a adesão ao tratamento, segundo a percepção de PVHA e que estão em tratamento de TB? Neste sentido, o objetivo do estudo foi analisar aspectos relacionados à adesão ao tratamento da tuberculose em pessoas que vivem com a coinfecção tuberculose/HIV.

\section{Métodos}

Trata-se de um estudo exploratório, do tipo descritivo, com abordagem qualitativa sobre a adesão ao tratamento da TB entre pessoas que apresentam a coinfecção TB/HIV. O cenário do estudo foi um centro de referência para HIV/aids do estado de São Paulo, localizado na capital. Trata-se de uma unidade de referência normativa, de avaliação e de coordenação do Programa Estadual para Prevenção, Controle, Diagnóstico e Tratamento de Infecçóes Sexualmente Transmissíveis (IST) e da Síndrome da Imunodeficiência Adquirida (AIDS) que atente usuários que residem no município e adjacentes. O serviço é um complexo ambulatorial e hospitalar com aproximadamente 800 funcionários, entre eles: médicos de diferentes especialidades, enfermeiros, dentistas, farmacêuticos, nutricionistas, psicólogos, assistente social, técnicos de laboratório e de enfermagem e oficiais administrativos.

Os critérios de elegibilidade foram: pessoas com idade igual ou superior a 18 anos, independentemente do sexo, que apresentaram resultado de sorologia reagente para o HIV, tendo desenvolvido ou não a Síndrome, que realizavam o tratamento para TB e TARV há pelo menos um mês e que apresentavam condiçôes cognitivas e físicas para participar do estudo.

No período da coleta de dados havia 18 pessoas com a coinfecção TB/HIV em tratamento de TB. Foi utilizada amostragem de conveniência, sendo que todos os usuários do centro de referência em HIV/aids, que se encontravam em tratamento para a TB, foram convidados a participar do estudo durante o comparecimento à consulta médica ou para a realização da supervisão do tratamento medicamentoso. A coleta de dados ocorreu no período de abril a agosto de 2019 e foi realizada por um aluno de graduação em Enfermagem, que foi devidamente capacitado para entrevistar os participantes do estudo. As entrevistas foram realizadas individualmente, em um ambiente reservado nas dependências do serviço de saúde, a fim de garantir a privacidade.

$\mathrm{O}$ instrumento de coleta de dados continha questôes relacionadas ao perfil sóciodemográfico e de saúde e as seguintes questóes norteadoras: 1) "Conte-me como começou a história da tuberculose para o Sr. (a.). 2) O tratamento da TB e do HIV fez com que aparecessem necessidades que o Sr (a). não tinha antes? e 3) Quais são as facilidades e as dificuldades em relação ao tratamento? Cada entrevista durou em média 25 minutos; os depoimentos foram gravados e transcritos na íntegra pelo mesmo entrevistador. Em seguida, os depoimentos foram identificados por uma letra seguida de um número arábico a fim de garantir o anonimato. Foi realizada a leitura em profundidade e exaustiva das entrevistas para apreender os significados da adesão ao tratamento de pessoas que vivenciam a coinfecção TB/HIV.

Este estudo adotou o conceito de adesão que envolve três planos: 1) refere-se à concepção de 
saúde-doença da pessoa em tratamento, o que pode significar maior passividade ou pró-atividade no enfrentamento do processo saúde-doença; 2) o lugar social ocupado pela pessoa doente, entendendo-se que a inserçáo na sociedade determina o acesso à vida com dignidade e as potencialidades para o enfrentamento dos processos que conduzem aos desgastes na condução da vida; e 3) o plano que trata do processo de produção da saúde, ou seja, a forma como os serviços de saúde se organizam para oferecer e realizar o cuidado em saúde. Estes elementos constitutivos do conceito de adesão contribuem para ampliar a compreensão do processo saúde-doença. ${ }^{(9)}$

Para a análise do material empírico foi utilizado o método de análise de discurso que permitiu a depreensão de frases temáticas. As ideias e os discursos são expressóes da vida real, contendo as visóes de mundo das pessoas, que se materializam nas representaçôes a respeito dos elementos da realidade objetiva. ${ }^{(10)} \mathrm{A}$ análise dos discursos foi realizada à luz da determinação social do processo saúde-doença.

O projeto foi aprovado por Comitê de Ética em Pesquisa (parecer número: 3.732.087) (CAAE: 91820618.0.0000.5505) e pelo Comitê de Ética em Pesquisa do serviço de saúde onde ocorreram as entrevistas (parecer número: 3.806.049) (CAAE: 91820618.0.3001.5375). Os entrevistados que participaram da pesquisa assinaram o Termo de Consentimento Livre e Esclarecido.

\section{Resultados}

Do total de 18 pessoas convidadas a participar da pesquisa, obteve-se duas recusas, justificadas pela impossibilidade de permanecer no serviço por um período mais prolongado de tempo. Foram entrevistadas 16 pessoas, sendo a maioria do sexo masculino $(\mathrm{n}=12)$, da cor parda $(\mathrm{n}=9)$, a faixa etária predominante foi a de 30 a 39 anos $(n=6)$, com 9 a 12 anos de estudo $(n=10)$, moravam sozinhos $(n=7)$, solteiros $(n=14)$ e se declararam homens que fazem sexo com homens $(n=10)$. A tabela 1 apresenta a descrição das condições de trabalho, vida e relacionadas ao processo saúde-doença.
Tabela 1. Características sociodemográficas e de saúde das pessoas que vivem com HIV/aids em tratamento para tuberculose

\begin{tabular}{lc}
\hline Variáveis & $\mathbf{n}(\%)$ \\
\hline Características das condições de trabalho & \\
Trabalha & $5(31,3)$ \\
Não trabalha & $9(56,2)$ \\
Aposentado & $2(12,5)$ \\
Características das condições de vida & \\
Renda (salário mínimo) & \\
Até 1 & \\
2 a 3 & $6(37,5)$ \\
$>3$ & $5(31,3)$ \\
Exposição ao HIV & $5(31,3)$ \\
Sexual & \\
Outra & $14(87,5)$ \\
Tempo de Diagnóstico do HIV (anos) & $2(12,5)$ \\
$>10$ & \\
1 a 9 & $9(56,3)$ \\
$<1$ & $2(12,5)$ \\
Carga Viral (cópias/mL) & $5(31,2)$ \\
$<50$ (indetectável) & \\
50 a 20.000 & $7(43,7)$ \\
Contagem de células T-CD4+ & $9(56,3)$ \\
$>350$ & \\
200 a 350 & $3(18,8)$ \\
$<200$ & $6(37,5)$ \\
Forma Clínica da Tuberculose & $7(43,7)$ \\
Pulmonar & \\
Extrapulmonar & $12(75)$ \\
Extrapulmonar + pulmonar & $1(6,2)$ \\
Tempo de Tratamento da Tuberculose (dias) & $3(18,8)$ \\
31 a 90 & \\
91 a 360 & $10(62,5)$ \\
$>360$ & $5(31,2)$ \\
\hline
\end{tabular}

*Usuário na segunda tentativa de tratamento no mesmo ano

A análise dos depoimentos evidenciou que a adesão ao tratamento é percebida como algo complexo, envolvendo aspectos que transcendem aqueles relativos à clínica da doença, ampliando-se para questóes de ordem social. Do processo de análise emergiram três categorias de análise: Processo saúde doença, Tratamento medicamentoso e Cuidado nos serviços de saúde. $\mathrm{O}$ quadro 1 apresenta as categorias analíticas e seus respectivos elementos constitutivos.

Quadro 1. Categorias de análise e elementos constitutivos da adesão ao tratamento da tuberculose entre pessoas que vivem com HIV/aids

\begin{tabular}{|c|c|c|}
\hline $\begin{array}{l}\text { Processo saúde-doença: } 0 \\
\text { impacto do diagnóstico e } \\
\text { os significados de viver a } \\
\text { coinfecção }\end{array}$ & $\begin{array}{l}\text { Tratamento } \\
\text { medicamentoso: motivos } \\
\text { para o seguimento, } \\
\text { facilidades e dificuldades } \\
\text { envolvidas }\end{array}$ & $\begin{array}{l}\text { Cuidado no serviço de } \\
\text { saúde: acolhimento } \\
\text { e redes de apoio que } \\
\text { favorecem a adesão ao } \\
\text { tratamento. }\end{array}$ \\
\hline $\begin{array}{l}\text { - Impacto do diagnóstico } \\
\text { - Significados de viver com a } \\
\text { coinfecção TB/HIV } \\
\text { - Condições de saúde }\end{array}$ & $\begin{array}{l}\text { - Motivos para realizar } 0 \\
\text { tratamento } \\
\text { - Facilidades e dificuldades } \\
\text { no tratamento }\end{array}$ & $\begin{array}{l}\text { - Cuidado ofertado } \\
\text { - Acolhimento } \\
\text { - Rede de apoio }\end{array}$ \\
\hline
\end{tabular}

Em relação à categoria Processo saúde-doença, a análise dos depoimentos evidenciou que vivenciar a coinfecção TB/HIV é um processo multifaceta- 
do. Para alguns entrevistados, a TB representava um alerta para que o tratamento do HIV fosse retomado, desmistificando a falsa sensação do "eu não tenho nada” (E2). Para outros, a busca por assistência foi motivada por um quadro gripal que se intensificou com "febre e muita dor no pulmão" (E12) e que possibilitou o diagnóstico tanto da TB quanto do HIV. Com isso, ocorreram mudanças na vida cotidiana como forma de adaptação às enfermidades, sendo que as mais citadas foram: deixar de sair rotineiramente, priorizar o cuidado com a saúde, além da busca por conhecimento em relaçáo ao HIV, à TB e outras doenças oportunistas.

Foi comum o sentimento de surpresa e medo ao se obter o diagnóstico de TB e de HIV, conforme ilustra o seguinte depoimento: "quando eu descobri o HIV, foi um baque, eu queria me matar, porque eu nâo tinha conhecimento da doença" (E6). Com o diagnóstico da TB, foram mencionados sentimentos de medo, pânico, além da intensificação da sintomatologia da doença: "não conseguia dormir à noite, transpirava muito, e uma tosse que não passava" (E10), "muita febre, aquela suadeira, falta de apetite" (E11).

Alguns participantes que não haviam realizado a TARV referiram que a condição de saúde se tornou comprometida com a infecção pelo HIV: " $f$ quei debilitada" (E11), "não sentia os movimentos das pernas" (E3), "tinha dor de cabeça, sonolência” (E10).

Em relação às mudanças na vida, um dos entrevistados relatou que, por ter se infectado pelo HIV ainda na adolescência (E2), não se recordava de sua vida anteriormente a esse período; além disso, alguns entrevistados (E4, E5) que relataram ter tido o diagnóstico do HIV em época em que ainda não havia a TARV, ponderaram que, por serem assintomáticos, preocuparam-se com a doença apenas após vivenciarem o falecimento de pessoas próximas. Outros ainda mencionaram que o diagnóstico da TB ou do HIV trouxe repercussões na saúde mental, como pensamentos suicidas (E6, E8).

Soma-se a isso, questóes de ordem social advindas do diagnóstico da coinfecção TB/HIV. Os entrevistados referiram que expor o tratamento e o estado sorológico afetou diretamente o cotidiano e as relaçóes interpessoais: "Acho que eu tenho muita dificuldade de associar, no meu social, né" (E2). "eu não consigo mais me relacionar com ninguém” (E10).

Já em relaçáo à categoria Tratamento medicamentoso, dentre os motivos para seguir o tratamento, foram mencionados a busca por qualidade de vida e o medo de morrer. A experiência de vivenciar a coinfecção TB/HIV refletiu no compromisso de realizar o tratamento medicamentoso. Segundo um dos entrevistados, o diagnóstico da TB determinou que buscasse retomar a TARV: "é uma hora boa, porque esse apavoro faz com que eu me agarre ao tratamento (E2).

Por outro lado, o tratamento vai além da ingestâo dos medicamentos e envolve questóes de ordem moral, religiosa e sexual: "vai um pouco além disso, são situaçóes que estou tratando agora, tenho um abuso de infância, uma hiperestimulação sexual, uma repressão religiosa" (E2).

$\mathrm{O}$ apoio familiar revelou-se de diferentes formas, que interferem diretamente no seguimento da terapêutica. A aceitação da orientação sexual e do estado sorológico, por parte da família, foram percebidos como positivos, possibilitando o fortalecimento para o seguimento do tratamento "Ela [máe] é suporte para tudo, é minha vida, meu tudo, ela que hoje me faz viver" (E11). O contrário ocorre quando os familiares apresentaram atitudes de negação ou até mesmo de exclusão, como: "ontem meu pai falou para eu sair de casa, eu não sei se por causa da TB também, ele já não me aceita" (E1).

A coinfecção TB/HIV revelou-se como suporte para a adesáo ao tratamento. Alguns usuários relataram que o estado de debilidade física fez com que se sentissem obrigados a seguir o tratamento: "coloquei na cabeça: só tem um jeito, ou morrer ou se tratar"(E6); "Ah, botei na minha mente um objetivo que quero que isso dai saia de mim, ai eu penso todo dia em tomar remédio"(E3).

Em relação às facilidades para seguir o esquema terapêutico, os participantes relataram que o vínculo estabelecido com o serviço de saúde favoreceu a adesão ao tratamento, principalmente por sentirem-se acolhidos e livres de preconceitos "fui acolhido, bem tratado, em quatro dias eu levantei da cama, ... tenho a confiança de chegar aqui e me abrir"(E11). O fornecimento dos medicamentos e de suplemento alimentar pela rede pública, a facilidade de acesso ao 
serviço e o vínculo com a equipe de saúde também foram apontados como facilitadores para o seguimento do tratamento.

Por outro lado, o estigma social repercute negativamente na vida das pessoas que vivenciam a coinfecção TB/HIV, dificultando a adesão ao tratamento: "passei um ano recolhido, não queria ver nem conversar com ninguém, só sabia manter distância, eu me isolei por um ano, ou por preconceito meu em relaçâo à doença, ou por preconceito dos outros" (E9)

Além disso, alguns relatos mencionaram que os cuidados em saúde tornam a rotina de tratamento estressante: "minha vida é só médico" (E10), o que leva o usuário a refletir: "vou ter que tomar os remédios todos os dias para o resto da minha vida, é uma coisa que eu não queria pra mim" (E7).

Por fim, a categoria "Cuidado no serviço de saúde", revelou que o acolhimento do usuário representa um dos principais pilares para a adesão ao tratamento da coinfecção TB/HIV ("o pessoal se preocupa cada vez mais, com o todo da pessoa, não é?"(E8), uma vez que constitui uma rede de apoio. Destacam-se também o vínculo com a equipe de saúde e o fornecimento de cestas básicas. A maioria dos entrevistados referiu que a disponibilização gratuita de medicamentos e suplementos alimentares, a possibilidade de realizar os exames laboratoriais e o acompanhamento multiprofissional do serviço foram fundamentais para dar seguimento ao manejo clínico da coinfecção. Assim, mesmo residindo distante do serviço, o usuário optou pela realizaçáo do tratamento no serviço onde se realizou o presente estudo.

\section{Discussão}

Os depoimentos evidenciaram que a adesão não se reduz a um ato de volição pessoal e de cunho exclusivamente individual, mas está associada a outras dimensões, como o acolhimento do usuário na unidade de saúde e o apoio familiar. ${ }^{(11)} \mathrm{A}$ adesão ao tratamento não se reduz à aceitação da terapia medicamentosa, mas é um processo de múltiplas facetas, envolvendo a equipe multidisciplinar e a co-responsabilização com o usuário. Estudo realizado no município de Campinas, com pessoas em tratamen- to de TB, evidenciou a importância da educação em saúde, ao se ofertar informaçóes e orientações em relação à doença e ao tratamento, como forma de melhorar a adesão ao tratamento. ${ }^{(12)}$

Os depoimentos foram explícitos ao denotar que a adesão ao tratamento está fortemente relacionada à forma como o serviço de saúde recebe o usuário, ao oferecer atenção de qualidade e humanizada.

A importância do vínculo entre a equipe multidisciplinar e o usuário foi ressaltada nos depoimentos e se constitui em facilitador da adesão ao tratamento, uma vez que possibilita o cuidado centrado no usuário e em suas necessidades em saúde, individualizando o tratamento. O compartilhamento de decisóes para a definição de uma conduta aproxima o usuário da equipe de saúde, determinando que ele recorra à unidade de saúde quando necessário. Este achado corrobora estudo que traz como elementos de sucesso para o programa de tratamento, o cuidado centrado no usuário, baseado no acompanhamento e aconselhamento que incentivam a auto gestão do cuidado em saúde. ${ }^{(13)}$

Nessa mesma linha, os depoimentos evidenciaram que os incentivos recebidos contribuíram para o fortalecimento da adesão ao tratamento, principalmente em casos de vulnerabilidade social. Autores advogam que apesar de não ser a solução para os problemas e necessidades em saúde, os incentivos minimizam a situação de sofrimento das pessoas acometidas e, mais do que isso, a proteção social deve constituir a estrutura da sociedade. ${ }^{(11)}$

Um estudo realizado na Ucrânia, com o objetivo de identificar os desafios da adesão, na perspectiva dos pacientes durante o tratamento de TB, ressalta que o tempo e o custo do deslocamento para a realização do tratamento representaram obstáculos para a adesão, além da ausência de escuta qualificada e do acolhimento do usuário. ${ }^{(14)}$ A análise dos depoimentos do presente estudo mostrou que, apesar do tempo despendido para o deslocamento, do custo e do tempo de espera para o atendimento, os usuários optaram por realizar o seguimento do tratamento neste serviço de saúde em decorrência da qualidade do atendimento e do vínculo estabelecido com os profissionais de saúde. Esse serviço foi compreendido pelos participantes como um local que atende às 
necessidades em saúde no tratamento tanto do HIV quanto da TB.

Numa outra linha, o estigma social decorrente do HIV e da TB pode afetar a adesão ao tratamento. Quando o preconceito ocorre no âmbito familiar e social, a probabilidade de não adesão torna-se mais elevada. Os resultados do presente estudo corroboram os achados de uma investigação realizada em duas províncias da África do Sul, que investigou a adesão simultânea do tratamento para TB e da TARV, a fim de identificar os fatores de risco da não adesão aos tratamentos. Os resultados apontaram melhora da adesão e dos cuidados com a saúde no caso daqueles que divulgaram seu estado sorológico para familiares e amigos e que contavam o seu apoio para lembrá-los da tomada dos medicamentos. ${ }^{(15)}$

Os achados deste estudo vão ao encontro de um estudo nacional que apontou que o desejo de viver das pessoas com a coinfecção TB/HIV foi essencial para a adesão ao tratamento, pois permite a superação de barreiras impostas pela condição de saúde. ${ }^{(16)}$ De fato, os entrevistados referiram que a busca pela qualidade de vida e o medo de morrer foram motivos para a procura pelo serviço de saúde e a adesão ao tratamento.

Os depoimentos revelaram que o atendimento de qualidade é determinante para o seguimento do tratamento, acrescido da facilidade de acesso, da boa relação com a equipe multiprofissional e do fornecimento de medicamentos e suplementos alimentares. Sabe-se que a insatisfação com o serviço de saúde e a espera prolongada para os atendimentos pode influenciar negativamente a adesáo ao tratamento, desvinculando o usuário do serviço. Portanto, quando o processo de produção da saúde envolve o indivíduo, o seguimento do tratamento também é favorecido. ${ }^{(17)}$

No âmbito do manejo terapêutico do tratamento na coinfecção, os participantes referiram que o adoecimento por TB trouxe à tona a necessidade de retomar a TARV e os cuidados em saúde, representando um dos motivos para a adesão ao tratamento. Por outro lado, uma pesquisa realizada no Rio de Janeiro demonstrou que o impacto do diagnóstico da TB está diretamente associado à aceitação da condição sorológica, uma vez que o diagnóstico da coinfecção refletiu em descuido com a saúde, e a TB representava uma doença que agrava e dificultava a vivência com o HIV. ${ }^{(18)}$
O comportamento do usuário pode não ser o mesmo para cada regime terapêutico, dada a complexidade intrínseca específica. Assim como os relatos observados nas entrevistas, este estudo revelou que os efeitos adversos, o isolamento social, e a estigmatização da coinfecção influenciaram negativamente a adesão ao tratamento. Confirma-se, então, a necessidade de um modelo de assistência voltado ao manejo terapêutico da coinfecção e de suas particularidades. ${ }^{(19)}$

Pesquisa realizada no estado do Ceará, com o objetivo de avaliar a adesão à TARV em pessoas coinfectadas pela TB/HIV constatou que a adesão ao tratamento foi menor em pessoas coinfectados. ${ }^{(20)}$ A população do presente estudo se assemelha aos entrevistados desta pesquisa, pois a maioria era do sexo masculino e encontrava-se na faixa etária de 30 a 39 anos, que representa uma parcela da população economicamente ativa. Os achados semelhantes reforçam a necessidade da realizaçáo de programas terapêuticos voltados a esse grupo populacional e que levem em consideração as especificidades da adesão ao tratamento em pessoas que apresentam coinfecção.

Visto que a coinfecção TB-HIV continua sendo um desafio para o controle da TB e do HIV, os resultados desta pesquisa reforçam a necessidade de implementação de açóes colaborativas entre as duas enfermidades, considerando a articulação das redes de atenção em saúde, de forma a ofertar um atendimento integral e qualificado voltado para atender as necessidades em saúde das PVHA e que realizam o tratamento da TB.

Uma possível limitação do estudo diz respeito à pesquisa ter sido realizada em apenas um serviço de referência para o atendimento de PVHA. No entanto, dada a riqueza dos depoimentos, acredita-se que as informaçóes possibilitam uma reflexão no que diz respeito à adesão ao tratamento na percepçáo de PVHA em tratamento de TB.

\section{Conclusão}

O presente estudo investigou questóes vinculadas à adesão ao tratamento na coinfecção TB/HIV e perpassam o processo saúde doença, o tratamento 
medicamentoso e o cuidado nos serviços de saúde. Neste sentido, destaca-se que a formação de vínculo entre o usuário e o profissional de saúde favorece a adesão, bem como as redes de apoio e o fornecimento de benefícios. Ao mesmo tempo, o estigma social e o preconceito que envolvem ambas as condiçôes podem interferir na adesão ao tratamento. Os achados desta pesquisa corroboram os pilares da Estratégia Fim da TB da OMS, uma vez que demonstram a importância do cuidado centrado no paciente e integrado aos demais cuidados, a vinculação com políticas arrojadas que permitam o acesso ao tratamento e a serviços de saúde de qualidade capazes de estabelecer vínculo com o usuário.

\section{Agradecimentos}

À Fundação de Amparo à Pesquisa de São Paulo (FAPESP) pela concessão da bolsa de iniciação científica (Processo 2018/02915-0).

\section{Colaborações}

Silva ARS, Hino P, Bertolozzi MR, Oliveira JC, Carvalho MVF, Fernandes $\mathrm{H}$ e Sakabe $S$ declaram que contribuíram com a concepção do projeto, análise e interpretação dos dados, redação do artigo, revisão crítica do conteúdo intelectual e aprovação final da versão a ser publicada.

\section{Referências}

1. Brasil. Ministério da Saúde. Secretaria de Vigilância em Saúde. Departamento de Vigilância das Doenças Transmissíveis. Brasil Livre da Tuberculose: Plano Nacional pelo Fim da Tuberculose como Problema de Saúde Pública. Brasília (DF): Ministério da Saúde; 2017

2. World Health Organization (WHO). Global Tuberculosis Report 2020. Geneva: WHO; 2020. [cited 2021 Mar 24]. Available from: https:// www.who.int/publications//item/9789240013131

3. Brasil. Ministério da Saúde. Departamento de Doenças de Condições Crônicas e Infecções Sexualmente Transmissivveis. Tuberculose 2020. Bol Epidemiol. 2020; (no. espec):1-19.

4. Brasil. Ministério da Saúde. Panorama epidemiológico da co-infecção TB-HIV no Brasil 2019. Bol Epidemiol. 2019;50(26):1-23.
5. Swindells S, Ramchandani R, Gupta A, Benson CA, Leon-Cruz J, Mwelase N, et al.; BRIEF TB/A5279 Study Team. One month of rifapentine plus isoniazid to prevent HIV-related tuberculosis. N Engl J Med. 2019;380(11):1001-11.

6. Trajman A, Saraceni V, Durovni B. Os Objetivos do Desenvolvimento Sustentável e a tuberculose no Brasil: desafios e potencialidades. Cad Saude Publica. 2018;34(6):e00030318.

7. Kanu NE, Tobin-West $\mathrm{Cl}$. Health-related quality of life of HIV patients with and with out tuberculosis registered in a Tertiary Hospital in Port Harcourt, Nigeria. HIV AIDS Rev. 2018;17(3):210-7.

8. Brasil. Ministério da Saúde. Secretaria de Vigilância em Saúde. Departamento de Vigilância, Prevenção e Controle das Infecções Sexualmente Transmissíveis, do HIV/Aids e das hepatites Virais. Protocolo clínico e diretrizes terapêuticas para manejo da infecção pelo hiv em adultos. Brasília: Ministério da Saúde; 2017.

9. Bertolozzi MR, Nichiata LYI, Takahashi RF, Ciosak SI, Hino P, Val LF, et al. Os conceitos de vulnerabilidade e adesão na Saúde Coletiva. Rev Esc Enferm 2009; 43(Esp 2):1326-30.

10. Fiorin JL, Savioli FP. Para entender o texto: leitura e redação. São Paulo: Ática; 1991.

11. Orlandi GM, Pereira ÉG, Biagolini RE, França FO, Bertolozzi MR. Social incentives for adherence to tuberculosis treatment. Rev Bras Enferm. 2019;72(5):1182-8.

12. Beraldo $A A$, Andrade RL, Orfão NH, Silva-Sobrinho RA, Pinto ES, Wysoccki $A D$, et al. Adesão ao tratamento da tuberculose na Atenção Básica: percepção de doentes e profissionais em município de grande porte. Rev Enferm Anna Nery. 2017;21(4):e20170075.

13. O'Donnell MR, Daftary A, Frick M, Hirsch-Moverman Y, Amico KR, Senthilingam $M$, et al. Re-inventing adherence: toward a patientcentered model of care for drug-resistant tuberculosis and HIV. Int J Tuberc Lung Dis. 2016;20(4):430-4.

14. Aibana O, Dauria E, Kiriazova T, Makarenko O, Bachmaha M, Rybak N, et al. Patients' perspectives of tuberculosis treatment challenges and barriers to treatment adherence in Ukraine: a qualitative study. BMJ Open. 2020;10(1):e032027.

15. Webb Mazinyo E, Kim L, Masuku S, Lancaster JL, Odendaal R, Uys M, et al. Adherence to Concurrent Tuberculosis Treatment and Antiretroviral Treatment among Co-Infected Persons in South Africa, 2008-2010. PLoS One. 2016;11(7):e0159317.

16. Ferreira KR, Orlandi GM, Silva TC, Bertolozzi MR, França FO, Bender A. Representations on adherence to the treatment of Multidrug-Resistant Tuberculosis. Rev Esc Enferm USP. 2018;52(0):e03412.

17. Tesfahuneygn G, Medhin G, Legesse M. Adherence to Anti-tuberculosis treatment and treatment outcomes among tuberculosis patients in Alamata District, northeast Ethiopia. BMC Res Notes. 2015;8(1):503.

18. Silva JB, Cardoso GC, Ruffino Netto A, kritski AL. Os significados da comorbidade para os pacientes vivendo com TB/HIV: repercussões no tratamento. Physis. 2015; 25(1):209-29.

19. Daftary A, Padayatchi N, O'Donnell M. Preferential adherence to antiretroviral therapy over tuberculosis treatment: a qualitative study of drug-resistant TB/HIV co-infected patients in South Africa. Glob Public Health. 2014;9(9):1107-16.

20. Lemos LA, Fiuza ML, Reis RK, Ferrer AC, Gir E, Galvão MT. Adesão aos antirretrovirais em pessoas com coinfecção pelo vírus da imunodeficiência humana e tuberculose. Rev Lat Am Enfermagem. 2016;24:e2691. 